\title{
Lipoprotein (a) predicts recurrent worse outcomes in type 2 diabetes mellitus patients with prior cardiovascular events: a prospective, observational cohort study
}

Yan Zhang ${ }^{1}$, Jing-Lu Jin ${ }^{1}$, Ye-Xuan Cao ${ }^{1}$, Hui-Wen Zhang ${ }^{1}$, Yuan-Lin Guo ${ }^{1}$, Na-Qiong Wu ${ }^{1}$, Cheng-Gang Zhu', Ying Gao', Qi Hua ${ }^{2}$, Yan-Fang Li ${ }^{3}$, Rui-Xia Xu and Jian-Jun Li ${ }^{1 *}$ (D)

\begin{abstract}
Background: Merging studies have reported the association of lipoprotein(a) [Lp(a)] with poor outcomes of coronary artery disease (CAD) in patients with type 2 diabetes mellitus (T2DM). However, the prognostic importance of Lp(a) for recurrent cardiovascular events (CVEs) is currently undetermined in patients with T2DM and prior CVEs.

Methods: From April 2011 to March 2017, we consecutively recruited 2284 T2DM patients with prior CVEs. Patients were categorized into low, medium, and high groups by Lp(a) levels and followed up for recurrent CVEs, including nonfatal acute myocardial infarction, stroke, and cardiovascular mortality. Kaplan-Meier, Cox regression and C-statistic analyses were performed.

Results: During 7613 patient-years'follow-up, 153 recurrent CVEs occurred. Lp(a) levels were significantly higher in patients with recurrent CVEs than counterparts (20.44 vs. $14.71 \mathrm{mg} / \mathrm{dL}, \mathrm{p}=0.002$ ). Kaplan-Meier analysis revealed that the event-free survival rate was dramatically lower in high and medium $L p(a)$ groups than that in low group irrespective of HBA1C status $(<7.0 \%$; $\geq 7.0 \%$, both $p<0.05)$. Furthermore, multivariate Cox regression models indicated that Lp(a) was independently associated with high risk of recurrent CVEs [HR(95\% Cl): 2.049 (1.308-3.212)], such data remains in different HBA1c status (HR(95\% Cl): $<7.0 \%, 2.009(1.051-3.840) ; \geq 7.0 \%, 2.162(1.148-4.073))$. Moreover, the results of $\mathrm{C}$-statistic were significantly improved by 0.029 when added $L p(a)$ to the Cox model.

Conclusions: Our data, for the first time, confirmed that Lp(a) was an independent predictor for recurrent CVEs in T2DM patients with prior CVEs, suggesting that $L p(a)$ measurement may help to further risk stratification for T2DM patients after they suffered a first CVE.
\end{abstract}

Keywords: CAD, HBA1c, Lp(a), Recurrent CVEs, T2DM

\footnotetext{
*Correspondence: 13901010368@163.com

${ }^{1}$ State Key Laboratory of Cardiovascular Disease, FuWai Hospital, National Center for Cardiovascular Diseases, Chinese Academy of Medical Sciences, Peking Union Medical College, BeiLiShi Road 167, Beijing 100037, China

Full list of author information is available at the end of the article
}

\begin{abstract}
Background
It has been demonstrated that atherosclerotic cardiovascular disease (ASCVD) is the leading causes of morbidity and mortality for individuals with type 2 diabetes mellitus (T2DM) [1, 2]. Common conditions coexisting with T2DM such as hypertension and dyslipidemia are clear risk factors for ASCVD [1, 2]. For the past decades, controlling multiple cardiovascular risk factors have shown
\end{abstract}

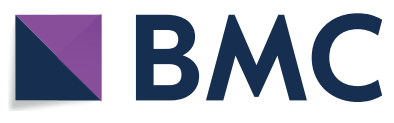

(c) The Author(s) 2020. This article is licensed under a Creative Commons Attribution 4.0 International License, which permits use, sharing, adaptation, distribution and reproduction in any medium or format, as long as you give appropriate credit to the original author(s) and the source, provide a link to the Creative Commons licence, and indicate if changes were made. The images or other third party material in this article are included in the article's Creative Commons licence, unless indicated otherwise in a credit line to the material. If material is not included in the article's Creative Commons licence and your intended use is not permitted by statutory regulation or exceeds the permitted use, you will need to obtain permission directly from the copyright holder. To view a copy of this licence, visit http://creativeco mmons.org/licenses/by/4.0/. The Creative Commons Public Domain Dedication waiver (http://creativecommons.org/publicdomain/ zero/1.0/) applies to the data made available in this article, unless otherwise stated in a credit line to the data. 
the efficacy of reducing or slowing ASCVD in people with T2DM [3]. However, the risk of recurrent major cardiovascular events (CVEs) remains high despite the intensive statin treatment and other secondary prevention strategies were recommended [4, 5]. Therefore, searching potential risk factors contributing to this residual cardiovascular risk is crucial for improving the longterm prognosis in patients with T2DM and a first CVE.

Elevated lipoprotein(a) (Lp[a]) represents one of the most common genetic dyslipidemias worldwide, affecting 1 in 5 individuals [6]. Close attention to $\mathrm{Lp}(\mathrm{a})$, a particle containing of a low-density lipoprotein (LDL)-like particle bound to apolipoprotein(a), has emergingly been paid due to its pathogenic role in atherosclerosis and thrombosis formation [6]. Epidemiological and prospective data have suggested that a high level of $L p(a)$ is an independent risk factor for incident cardiovascular disease (CVD) $[7,8]$, particularly among those with DM $[9,10]$. Simultaneously, in the secondary prevention setting, elevated $\mathrm{Lp}(\mathrm{a})$ values were also proved to be an independent predictor of CVEs in patients with established coronary artery disease (CAD) [11] or patients undergone percutaneous coronary intervention (PCI) $[12,13]$. Data from our team also delivered that $\mathrm{Lp}$ (a) levels were strongly associated with the presence and severity of CAD in individuals with DM [14] and could predict higher risk of subsequent CVEs in stable CAD patients with DM or pre-DM [15]. However, it is currently undetermined whether $L p(a)$ plays a role in predicting recurrent CVEs in patients who had experienced prior CVEs $[16,17]$, and even more, there is no large-scale study specific to the T2DM population.

Therefore, in this prospective, observational cohort study, we, for the first time, investigated the predictive value of $\mathrm{Lp}(\mathrm{a})$ with recurrent worse outcomes in T2DM patients with prior CVEs.

\section{Materials and methods Study population}

The study complied with the Declaration of Helsinki and was approved by the hospital's ethical review board (Fu Wai Hospital \& National Center for Cardiovascular Diseases, Beijing, China). All enrolled subjects provided informed written consent in the current study.

From April 2011 to March 2017 (as shown in Fig. 1), a total of $3690 \mathrm{~T} 2 \mathrm{DM}$ patients with angiography proven stable CAD were consecutively recruited from three medical centers, including FuWai hospital, XuanWu Hospital, and AnZhen hospital according to the same protocol. The blood samples for testing $\mathrm{Lp}(\mathrm{a})$ were sent to FuWai hospital for unified measurement. The inclusion criteria were patients who had experienced a prior CVE [defined as myocardial infarction (MI), stroke, peripheral arterial disease, percutaneous coronary intervention (PCI), and coronary artery bypass grafting (CABG)] between 2 months to 1 year before admission. The exclusion criteria were patients with significant hematologic disorders and infectious or systematic inflammatory disease; thyroid dysfunction, severe liver and/ or renal dysfunction; acute coronary syndrome (ACS), decompensated heart failure or arrhythmia; or malignant tumors, without detailed data. Finally, a total of 2310 eligible patients were enrolled in the current study. All study patients were prescribed secondary prevention medicine of ASCAD and followed up for adverse outcomes. Subsequently, a total of 26 patients were lost during the followup period. Therefore, there were 2284 T2DM patients with prior CVEs included in the final analysis, and were further divided into three groups according to $L p(a)$ levels.

\section{Follow-up}

Patients were followed up at 6 months' intervals through direct interviews or telephone by well-trained cardiologists or nurses who were blinded to the purpose of the study. The primary endpoints (recurrent CVEs) included cardiovascular death, non-fatal MI and stroke. For patients with suspected cardiovascular attacks, the medical records or emergency records were required to be sent to our centers. The endpoints were confirmed by at least two professional physicians.

\section{Definition of clinical status}

The diagnosis of Nonfatal MI included ST-segmentelevation MI (STEMI) and non-ST-segment-elevation MI (NSTEMI). STEMI was defined as elevated biomarkers and new or presumed new ST-segment elevation in 2 or more contiguous leads. NSTEMI was defined as the presence of elevated biomarkers and at least 1 of either ECG changes (ST-segment depression or T-wave abnormalities), or ischemic symptoms. Stroke was diagnosed by the presence of typical symptoms and imaging. DM was diagnosed by fasting plasma glucose $\geq 7.0 \mathrm{mmol} / \mathrm{L}$, the 2-h plasma glucose of the oral glucose tolerance test $(\mathrm{OGTT}) \geq 11.1 \mathrm{mmol} / \mathrm{L}$ (based on venous plasma glucose results before and $2 \mathrm{~h}$ after a $75 \mathrm{~g}$ oral glucose load), or current use of hypoglycemic drugs or insulin. Hypertension was defined as repeated systolic blood pressure $\geq 140 \mathrm{mmHg}$ or diastolic blood pressure $\geq 90 \mathrm{mmHg}$ (at least two times in different environments) or currently taking anti-hypertensive drugs. Dyslipidemia was defined by medical history or fasting total cholesterol $(\mathrm{TC}) \geq 5.18 \mathrm{mmol} / \mathrm{L}$ or triglyceride $(\mathrm{TG}) \geq 1.7 \mathrm{mmol} / \mathrm{L}$ and/or high-density lipoprotein cholesterol (HDLC) $<1.04 \mathrm{mmol} / \mathrm{L}$ (for male) or $<1.30 \mathrm{mmol} / \mathrm{L}$ (for female). Body mass index (BMI) was calculated as weight 


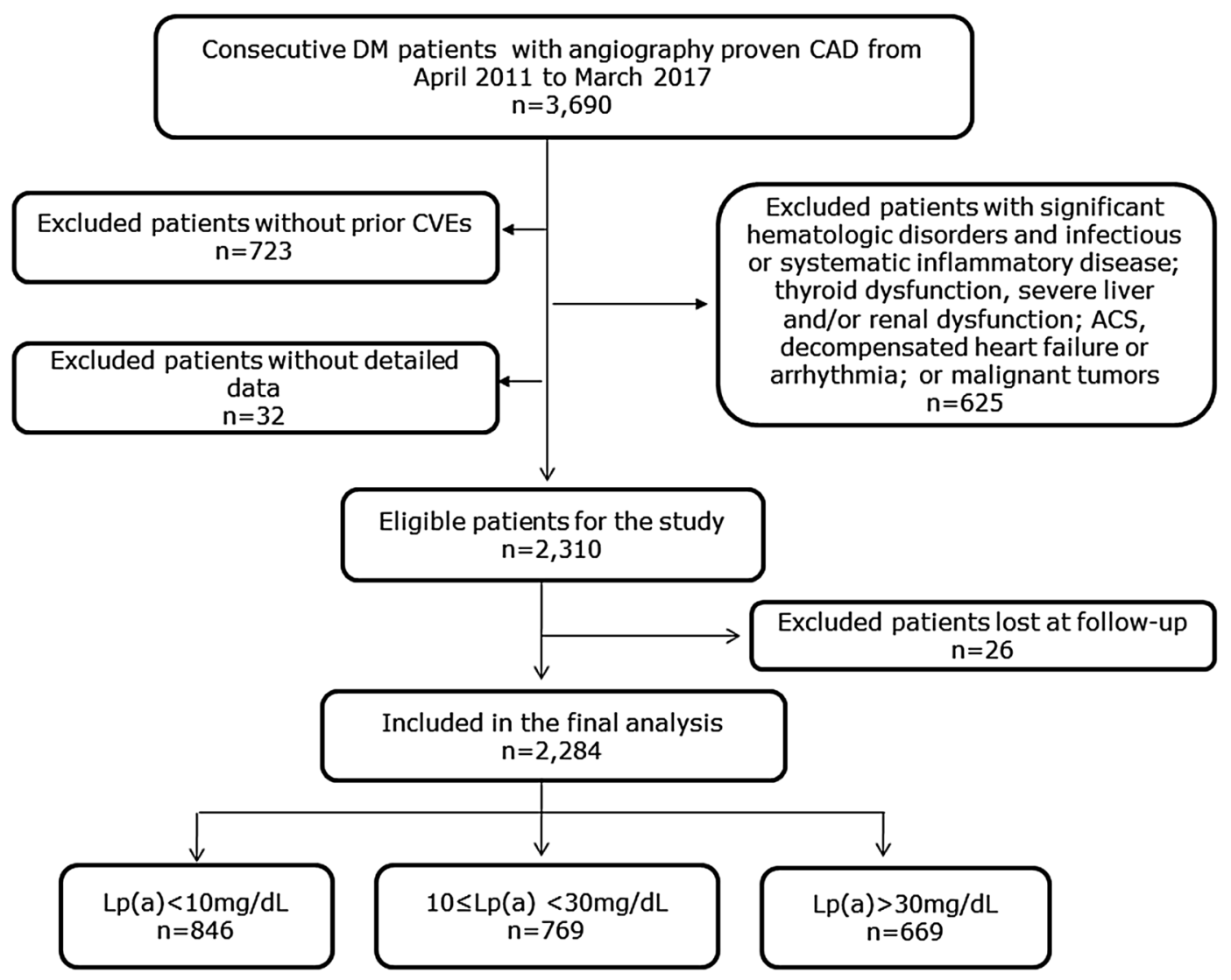

Fig. 1 Flowchart of the enrolled study population

(kg) divided by height $(\mathrm{m})$ squared. Overweight was defined as patients with $\mathrm{BMI} \geq 25 \mathrm{~kg} / \mathrm{m}^{2}$. Current smokers were defined as having smoked a cigarette in the past 30 days and $>100$ cigarettes in a lifetime. Family history of $\mathrm{CAD}$ was defined as $\mathrm{CAD}$ occurring in a first-degree relative including mother, father, siblings, or child.

\section{Laboratory analysis}

Blood samples were obtained from the cubital vein after at least $12 \mathrm{~h}$ of fasting in the current study. Concentrations of TC, TG, low density lipoprotein cholesterol (LDL-C), HDL-C levels were measured with an automatic biochemistry analyzer (7150; Hitachi, Tokyo, Japan) in an enzymatic assay. Apolipoprotein AI (apo $\mathrm{AI}$ ), and apo B were measured by an immunoturbidimetric method (Tina-quant, Roche Diagnostics). Lp(a) was determined by immunoturbidimetry method [LASAY Lp(a) auto; SHIMA Laboratories Co., Ltd] with a normal value of $<30 \mathrm{mg} / \mathrm{dL}$. An $\mathrm{Lp}(\mathrm{a})$ protein validated standard was used to calibrate the examination, and the coefficient of variation value of repetitive measurements was $<10 \%$. The concentrations of glucose were measured by enzymatic hexokinase method, and HbA1c by a Tosoh Automated Glycohemoglobin Analyzer HLC-723G8.

\section{Statistical analysis}

The data were expressed as the mean $\pm \mathrm{SD}$ or median (Q1-Q3) for the continuous variables and the number (percentage) for the categorical variables. The Kolmogorov-Smirnov test was used to test the distribution pattern. The differences between continuous variables were determined with the Student's $t$ test, analysis of variance, Mann-Whitney U test, Kruskal-Wallis $\mathrm{H}$ test, and between the categorical variables were analyzed by $\chi^{2}$-test or Fisher's exact test where appropriate. The event-free survival rates among groups were calculated by the Kaplan-Meier analysis and compared by the log-rank test. Univariate and multivariate Cox proportional hazard models were used to calculate the hazard ratio (HR) and 95\% confidence interval (CI). To identify whether $\mathrm{Lp}(\mathrm{a})$ could improve the prediction of recurrent CVEs based on the SMART risk score model [18], we calculated Harrell's C-statistic in the current analysis. A p-values of less than 0.05 were considered statistically significant. The statistical analyses were performed with 
SPSS version 22.0 software (SPSS Inc., Chicago, IL, USA) and R language version 3.6.3 (Feather Spray).

\section{Results}

\section{Baseline characteristics}

Consistent with previous researches $[19,20]$, the plasma lipoprotein(a) levels had a skewed distribution in the overall 2284 enrolled population (as shown in Fig. 2). Table 1 summarizes study sample characteristics stratified by $L p(a)$ levels (Low: $L p[a]<10 \mathrm{mg} / \mathrm{dL}, \mathrm{n}=846$; Medium: $10 \mathrm{mg} / \mathrm{dL} \leq \mathrm{Lp}[\mathrm{a}]<30 \mathrm{mg} / \mathrm{dL}, \mathrm{n}=769$; High: $\mathrm{Lp}[\mathrm{a}] \geq 30 \mathrm{mg} / \mathrm{dL}, \mathrm{n}=669$ ). Mean age of study participants was 58.54 years and $73.3 \%$ were male. Most participants were considered to have traditional CVD risk factors including hypertension (69.6\%), dyslipidemia (79.6\%), and current smokers (57.4\%), while only $13.7 \%$ of the enrolled patients have family history of CAD. Participants in the high $\mathrm{Lp}(\mathrm{a})$ group (Lp $[\mathrm{a}] \geq 30 \mathrm{mg} / \mathrm{dL}$ ) had less male patients, higher TC, LDL-C, apolipoprotein B levels, lower plasma TG levels, and tended to have more multi-diseased vessels.

Of these, $1311(57.4 \%)$ was only on oral anti-diabetes drugs, and 726 (31.8\%) had insulin treatment. Meanwhile, there was no significant difference with regard to anti-diabetes drug therapy as well as prescribed secondary prevention medicines such as aspirin, $\mathrm{P} 2 \mathrm{Y} 12$ inhibitor, statins, angiotensin converting enzyme inhibitor/ angiotensin receptor blockers (ACEI/ARB), $\beta$-blockers, and calcium channel blocker (CCB) among groups (Table 1).

\section{Relation of risk factors and recurrent CVEs}

Over 7613 patient-years' follow-up period, 153 recurrent CVEs occurred ( 68 been identified as cardiovascular death, 30 suffered nonfatal MI, and 55 had strokes) as shown in Table 2. Patients with recurrent CVEs were

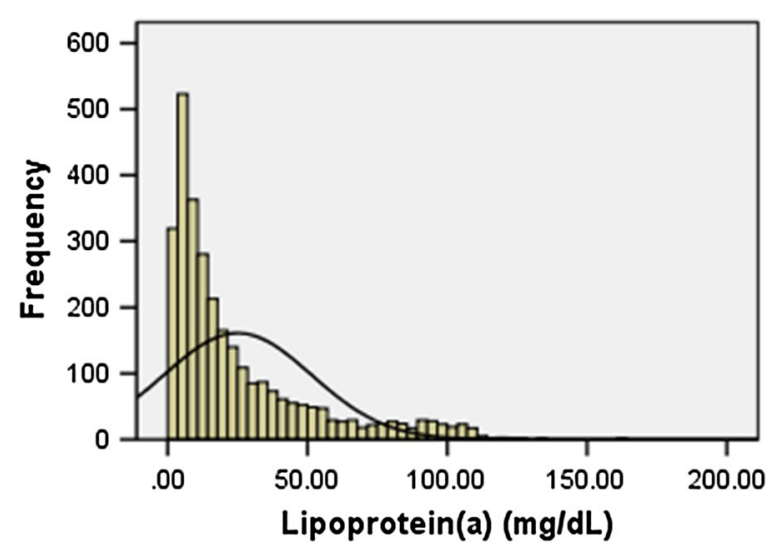

Fig. 2 The distribution of lipoprotein(a) levels in patients with DM much older, with lower percentage of overweight. Of note, the $\operatorname{Lp}(\mathrm{a})$ levels were dramatically higher in patients with recurrent CVEs compared with those without recurrent CVEs (20.44 $\mathrm{mg} / \mathrm{dL}$ vs. $14.71 \mathrm{mg} / \mathrm{dL}, \mathrm{p}=0.002)$. Nevertheless, the gender, blood pressure, heart rate, fasting blood glucose, HbA1c, TC, HDL-C, LDL-C, TG, apo A1, and apo B were balanced between patients with or without recurrent CVEs (all $p>0.05$ ). The association of exposure and other variables with recurrent CVEs in patients with T2DM were shown in Additional file 1: Table S2.

\section{Lp(a) levels and recurrent CVEs}

The incidence of the composite recurrent CVEs in the low, medium, and high Lp(a) groups (based on the cutoff value of 10 and $30 \mathrm{mg} / \mathrm{dL}$ ) was $4.4 \%, 7.7 \%$, and $8.5 \%$, respectively. As shown in Fig. 3a, the Kaplan-Meier analysis showed that subjects with medium and high $\mathrm{Lp}$ (a) value had a significantly lower cumulative eventfree survival rate compared to those with low $\operatorname{Lp}(\mathrm{a})$ value $(p=0.001)$. Similar results were found in patients with HbA1c $<7.0 \%$ ( $p=0.011$, Fig. $3 b)$ and HbA1c $\geq 7.0 \%$ $(\mathrm{p}=0.040$, Fig. $3 \mathrm{c})$ group.

As presented in Table 3, univariate Cox regression models showed that the hazard ratio of recurrent CVEs in patients with medium and high $\mathrm{Lp}$ (a) was 1.736 -fold, 1.960-fold higher than ones with low $\mathrm{Lp}(\mathrm{a})$ values. Additional adjustment for other variables did not change the significance of high $\mathrm{Lp}(\mathrm{a})$ with recurrent CVEs (HR 2.049 [95\% CI 1.308-3.212], $\mathrm{p}=0.002$ ). When divided the composite recurrent CVEs into three separate endpoints including non-fatal MI, stroke, and cardiovascular death, high Lp(a) group had a 3.016-fold hazard ratio of non-fatal MI $(\mathrm{p}=0.026)$, and a 2.708 -fold hazard ratio of cardiovascular death $(\mathrm{p}=0.006)$ compared with low $\mathrm{Lp}(\mathrm{a})$ group. However, high $\mathrm{Lp}(\mathrm{a})$ group did not have an increase in stroke risk compared with the low $\mathrm{Lp}(\mathrm{a})$ group $(p=0.777)$. Furthermore, the relationship of $L p(a)$ levels with recurrent CVEs did not impacted by HBA1c status (as indicated in Table 4, $\mathrm{p}<0.05$ ). In a sensitivity analysis by excluding individuals with CABG, stroke and peripheral arterial disease $(n=1758)$, high $\mathrm{Lp}(\mathrm{a})$ remains an independent predictor of recurrent CVEs in this population (medium Lp(a) categories: HR 2.244 [95\% CI 1.263-3.984], $\mathrm{p}=0.006$; high Lp(a) categories: HR 2.399 [95\% CI 1.313-4.383], $\mathrm{p}=0.004$; respectively) after adjusting for potential confounding factors (shown in Additional file 1: Table S1).

\section{Risk prediction for recurrent CVEs}

As presented in Table 5, in the whole population, Cox prediction using the SMART risk score model, the C-statistic values were 0.660 (95\% CI $0.595-0.726)$. 
Table 1 Baseline clinical characteristics of the study participants according to Lp(a) categories

\begin{tabular}{|c|c|c|c|c|c|}
\hline \multirow[t]{2}{*}{ Variables } & \multirow{2}{*}{$\begin{array}{l}\text { All patients } \\
(n=2284)\end{array}$} & \multicolumn{3}{|c|}{ Lp (a) categories (mg/dL) } & \multirow[t]{2}{*}{$p$ value } \\
\hline & & $\begin{array}{l}<10 \\
(n=846)\end{array}$ & $\begin{array}{l}10 \sim 30 \\
(n=769)\end{array}$ & $\begin{array}{l}\geq 30 \\
(n=669)\end{array}$ & \\
\hline \multicolumn{6}{|l|}{ Clinical characteristics } \\
\hline Age, years & $58.54 \pm 10.47$ & $57.99 \pm 10.66$ & $58.74 \pm 10.61$ & $59.00 \pm 10.06$ & 0.143 \\
\hline Male, n (\%) & $1674(73.3)$ & $663(78.4)$ & $550(71.5)$ & $461(68.9)$ & $<0.001$ \\
\hline Hypertension, n (\%) & 1589 (69.6) & $607(71.8)$ & $529(68.8)$ & $453(67.8)$ & 0.199 \\
\hline Dyslipidemia, n (\%) & $1817(79.6)$ & $677(80.1)$ & $612(79.7)$ & $528(79.0)$ & 0.885 \\
\hline Current smokers, n (\%) & $1312(57.4)$ & $507(59.9)$ & $445(57.9)$ & $360(53.8)$ & 0.052 \\
\hline Family history of CAD, n (\%) & $312(13.7)$ & $103(12.2)$ & $109(14.2)$ & $100(14.9)$ & 0.281 \\
\hline Body mass index, $\mathrm{kg} / \mathrm{m}^{2}$ & $26.35 \pm 3.15$ & $26.64 \pm 3.12$ & $26.18 \pm 3.27$ & $26.19 \pm 3.02$ & 0.005 \\
\hline $\mathrm{SBP}, \mathrm{mmHg}$ & $128 \pm 17$ & $128 \pm 17$ & $128 \pm 18$ & $127 \pm 16$ & 0.288 \\
\hline $\mathrm{DBP}, \mathrm{mmHg}$ & $78 \pm 16$ & $78 \pm 11$ & $78 \pm 22$ & $77 \pm 11$ & 0.133 \\
\hline Heart rate, bpm & $71 \pm 10$ & $72 \pm 10$ & $71 \pm 10$ & $71 \pm 11$ & 0.163 \\
\hline \multicolumn{6}{|c|}{ Laboratory and clinical parameters } \\
\hline $\mathrm{FBG}, \mathrm{mmol} / \mathrm{L}$ & $7.24 \pm 2.31$ & $7.33 \pm 2.35$ & $7.23 \pm 2.34$ & $7.12 \pm 2.24$ & 0.220 \\
\hline $\mathrm{HbA1c}, \%$ & $7.39 \pm 1.26$ & $7.35 \pm 1.22$ & $7.44 \pm 1.29$ & $7.38 \pm 1.28$ & 0.311 \\
\hline $\mathrm{TC}, \mathrm{mmol} / \mathrm{L}$ & $4.08 \pm 1.18$ & $3.97 \pm 1.21$ & $4.02 \pm 1.10$ & $4.29 \pm 1.20$ & $<0.001$ \\
\hline $\mathrm{HDL}-\mathrm{C}, \mathrm{mmol} / \mathrm{L}$ & $1.01 \pm 0.27$ & $1.00 \pm 0.27$ & $1.01 \pm 0.26$ & $1.03 \pm 0.28$ & 0.054 \\
\hline LDL-C, mmol/L & $2.45 \pm 0.97$ & $2.28 \pm 0.92$ & $2.42 \pm 0.90$ & $2.69 \pm 1.06$ & $<0.001$ \\
\hline $\mathrm{TG}, \mathrm{mmol} / \mathrm{L}$ & $1.56(1.17-2.20)$ & $1.65(1.19-2.42)$ & $1.54(1.16-2.14)$ & $1.48(1.13-2.09)$ & $<0.001$ \\
\hline $\mathrm{Lp}(\mathrm{a}), \mathrm{mg} / \mathrm{dL}$ & $15.01(6.60-34.76)$ & $5.22(3.32-7.33)$ & $17.19(13.11-22.54)$ & $52.94(38.85-79.41)$ & $<0.001$ \\
\hline ApoAl, g/L & $1.31 \pm 0.30$ & $1.32 \pm 0.35$ & $1.29 \pm 0.26$ & $1.31 \pm 0.29$ & 0.179 \\
\hline ApoB, g/L & $0.92 \pm 0.30$ & $0.87 \pm 0.29$ & $0.90 \pm 0.28$ & $0.99 \pm 0.31$ & $<0.001$ \\
\hline Diseased vessels, n (\%) & & & & & 0.016 \\
\hline One vessel & $430(18.8)$ & $174(20.6)$ & $151(19.6)$ & $105(15.7)$ & \\
\hline Two vessels & $677(29.6)$ & $273(32.3)$ & $218(28.4)$ & $186(27.8)$ & \\
\hline Multi-vessels & $1138(49.8)$ & $382(45.1)$ & $391(50.8)$ & $365(54.5)$ & \\
\hline LVEF, \% & $62.3 \pm 8.7$ & $62.3 \pm 8.8$ & $62.3 \pm 9.1$ & $62.2 \pm 8.2$ & 0.971 \\
\hline \multicolumn{6}{|l|}{ Medications } \\
\hline Aspirin, n (\%) & $2227(97.5)$ & $827(97.7)$ & $753(97.8)$ & $647(96.8)$ & 0.418 \\
\hline P2Y12 inhibitor, n (\%) & $2040(89.3)$ & $750(88.6)$ & $703(91.4)$ & $587(87.8)$ & 0.070 \\
\hline Statins, n (\%) & $2133(93.4)$ & $783(92.7)$ & $730(94.9)$ & $620(92.7)$ & 0.150 \\
\hline ACEI/ARB, n (\%) & $1215(53.2)$ & $453(53.6)$ & $402(52.3)$ & $360(53.8)$ & 0.825 \\
\hline$\beta$-blockers, n (\%) & $1886(82.6)$ & $711(84.0)$ & $617(80.2)$ & $558(83.4)$ & 0.117 \\
\hline CCB, n (\%) & $875(38.3)$ & $335(39.6)$ & $295(38.3)$ & $245(36.7)$ & 0.513 \\
\hline Anti-diabetes treatment & & & & & 0.757 \\
\hline Oral drugs & $1311(57.4)$ & $488(57.7)$ & $435(56.6)$ & $388(58.0)$ & \\
\hline Insulin & $726(31.8)$ & $259(30.6)$ & $254(33.0)$ & $213(31.9)$ & \\
\hline
\end{tabular}

Continuous values are summarized as mean \pm SD, median (Q1-Q3) and categorical variables as $\mathrm{n}(\%)$

$L p(a)$ lipoprotein(a), $C A D$ coronary artery disease, SBP systolic blood pressure, $D B P$ diastolic blood pressure, $F B G$ fasting blood glucose, $H b A 1 c$ glycosylated hemoglobin, $T C$ total cholesterol, $H D L$-C high-density lipoprotein cholesterol, $L D L-C$ low-density lipoprotein cholesterol, $T G$ triglyceride, $A p o A /$ apolipoprotein $\mathrm{Al}$, $A p o B$ apolipoprotein $B, L V E F$ left ventricular ejection fraction, $A C E l$ angiotensin converting enzyme inhibitors, $A R B$ angiotensin receptor blockers, $C C B$ calcium channel blockers

Furthermore, adding $\mathrm{Lp}(\mathrm{a})$ categories to the original model resulted in a significant improvement in C-statistic $(\Delta \mathrm{C}$-statistic $0.029[0.006-0.062], \mathrm{p}=0.047)$.

\section{Discussion}

Our study enrolled a prospective cohort corresponding to diabetic individuals with prior established CVEs, who were at high risk for recurrent ischemic CVEs in the circumstance of following standard secondary prevention 
Table 2 Clinical and traditional risk factors in patients with and without recurrent CVEs

\begin{tabular}{|c|c|c|c|}
\hline Characteristics & With recurrent CVEs ( $n=153$ ) & Without recurrent CVEs $(n=2131)$ & p value \\
\hline Age, years & $62.58 \pm 9.17$ & $58.25 \pm 10.50$ & $<0.001$ \\
\hline Male, n (\%) & $115(75.2)$ & $1559(73.2)$ & 0.637 \\
\hline Body mass index, $\mathrm{kg} / \mathrm{m}^{2}$ & $25.85 \pm 3.09$ & $26.39 \pm 3.15$ & 0.042 \\
\hline $\mathrm{BMl}<25 \mathrm{~kg} / \mathrm{m} 2$ & $70(45.9)$ & $718(33.7)$ & 0.003 \\
\hline $\mathrm{SBP}, \mathrm{mmHg}$ & $127 \pm 18$ & $128 \pm 17$ & 0.645 \\
\hline $\mathrm{SBP}<130 \mathrm{mmHg}$ & $78(51.2)$ & $1057(49.6)$ & 0.785 \\
\hline $\mathrm{DBP}, \mathrm{mmHg}$ & $76 \pm 10$ & $78 \pm 16$ & 0.130 \\
\hline $\mathrm{DBP}<80 \mathrm{mmHg}$ & $72(47.3)$ & $889(41.7)$ & 0.231 \\
\hline Heart rate, bpm & $71 \pm 10$ & $71 \pm 10$ & 0.761 \\
\hline \multicolumn{4}{|l|}{ Biochemical parameters } \\
\hline $\mathrm{FBG}, \mathrm{mmol} / \mathrm{L}$ & $7.12 \pm 2.43$ & $7.24 \pm 2.31$ & 0.526 \\
\hline FBG $4.4 \sim 6.5 \mathrm{mmol} / \mathrm{L}$ & $60(38.9)$ & $886(41.6)$ & 0.548 \\
\hline $\mathrm{HbA} 1 \mathrm{c}, \%$ & $7.53 \pm 1.37$ & $7.38 \pm 1.25$ & 0.150 \\
\hline $\mathrm{HbA} 1 \mathrm{c}<7.0 \%$ & $74(48.4)$ & $1072(50.3)$ & 0.932 \\
\hline $\mathrm{TC}, \mathrm{mmol} / \mathrm{L}$ & $4.03 \pm 1.08$ & $4.08 \pm 1.19$ & 0.618 \\
\hline $\mathrm{HDL}-\mathrm{C}, \mathrm{mmol} / \mathrm{L}$ & $0.99 \pm 0.26$ & $1.01 \pm 0.27$ & 0.325 \\
\hline $\mathrm{LDL}-\mathrm{C}, \mathrm{mmol} / \mathrm{L}$ & $2.44 \pm 0.93$ & $2.45 \pm 0.97$ & 0.942 \\
\hline $\mathrm{LDL}-\mathrm{C}<1.4 \mathrm{mmol} / \mathrm{L}$ & $16(10.6)$ & $232(10.9)$ & 0.907 \\
\hline $\mathrm{TG}, \mathrm{mmol} / \mathrm{L}$ & $1.54(1.17-2.12)$ & $1.56(1.17-2.20)$ & 0.502 \\
\hline $\mathrm{Lp}(\mathrm{a}), \mathrm{mg} / \mathrm{dL}$ & $20.44(10.01-43.96)$ & $14.71(6.43-34.16)$ & 0.002 \\
\hline ApoAl, g/L & $1.29 \pm 0.30$ & $1.31 \pm 0.30$ & 0.407 \\
\hline ApoB, g/L & $0.91 \pm 0.30$ & $0.92 \pm 0.30$ & 0.746 \\
\hline
\end{tabular}

Continuous values are summarized as mean $\pm S D$, median (Q1-Q3) and categorical variables as $\mathrm{n}$ (percentage)

CVEs cardiovascular events, SBP systolic blood pressure, DBP diastolic blood pressure, FBG fasting blood glucose, $H b A 1 \mathrm{c}$ glycosylated hemoglobin, $T C$ total cholesterol, $H D L-C$ high-density lipoprotein cholesterol, $L D L-C$ low-density lipoprotein cholesterol, $T G$ triglyceride, $L p(a)$ lipoprotein(a), $A p o A /$ apolipoprotein $A l, A p o B$ apolipoprotein B

strategies recommended by the current guidelines [21, 22]. Data, for the first time, clearly confirmed that $\operatorname{Lp}(\mathrm{a})$ was an independent predictor for recurrent CVEs in T2DM patients with prior CVEs. When stratified by HBA1c levels $(<7.0 \%$, or $\geq 7.0 \%)$, this association were significant in both HBA1c status independent of the level of the other risk factors. More importantly, in the overall cohort, the addition of $\operatorname{Lp}(\mathrm{a})$ to the model improved the risk prediction for recurrent CVEs. Thus, the present study strongly implied that Lp(a) might be a useful marker for further risk stratification in patients with T2DM after they suffered a first CVE.

The prevalence of T2DM has been increasing dramatically over the past few decades, with projections of an even greater growth over coming decades [23, 24]. Convincing evidence indicated that CAD is a common comorbidity in patients with T2DM and has been considered as a CAD risk equivalent based on multiple guidelines [25]. Currently, several clinical investigations indicated that despite aggressive multidisciplinary efforts have been made including revascularization and intensive management of LDL-C, glucose, blood pressure, and thrombotic risk, patients surviving an ACS event are at increased risk of recurrent CVEs, and this risk is further increased in patients with T2DM [26], raising the question of whether the treatment regimens are less effective in these patients. For decades, it has been well elucidated that abnormal lipid metabolism largely contributes to the additional cardiovascular risk for T2DM patients [27]. Therefore, the management of multiple risk factors especially lipid is of great significance for the prognosis. The recent guidelines have clearly recommended the target value of LDL-C [28], nonetheless, residual cardiovascular risk remains high for T2DM patients with a prior CVE compared with non-diabetic patients. Thus, it is essential to search additional modifiable lipid disorders to further improve the prognosis of these patients. Therefore, we consecutively recruited 2284 T2DM patients with prior CVEs and followed up for 7613 patient-years, attempting to seek plausible residual risk in terms of lipid disorders.

Recently, the relationship of elevated Lp(a) with CVD risk have been emergingly recognized in multiple investigations. Plasma concentrations of $\mathrm{Lp}$ (a) are mainly (90\%) determined by the LPA gene, without significant dietary or environmental influences [29]. The association of $\mathrm{Lp}(\mathrm{a})$ with risk of CAD as well as mortality, which is 


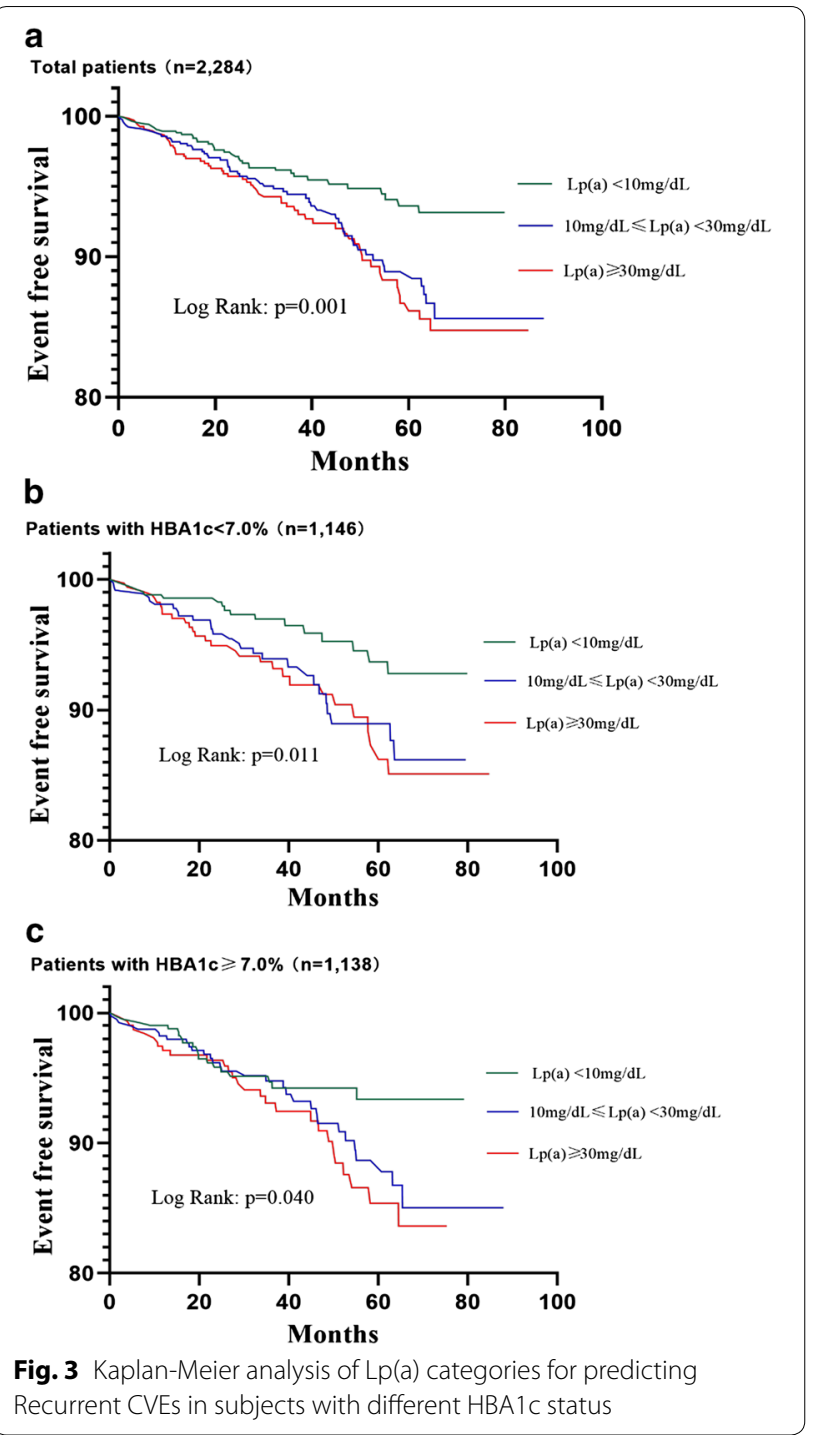

independent of traditional cardiovascular risk factors, has been rapidly aware in series of studies [7, 30]. Lp(a) has been determined as the independent genetic risk factor of CVD and a causal role has been demonstrated by Mendelian randomization [31]. The Copenhagen City Heart Study demonstrated that compared to subjects with $\mathrm{Lp}(\mathrm{a})$ levels below $5 \mathrm{mg} / \mathrm{dL}$, those with $\mathrm{Lp}$ (a) between 30 and $76 \mathrm{mg} / \mathrm{dL}$ had a 1.6-fold increased risk for incident MI. This risk increased to 1.90 for individuals with $\mathrm{Lp}(\mathrm{a})$ between 77 and $117 \mathrm{mg} / \mathrm{dL}$ and to 2.60 for individuals with $\mathrm{Lp}(\mathrm{a})$ concentrations above $117 \mathrm{mg} /$ $\mathrm{dL}$ [8]. However, the data mainly based on investigations of apparently healthy participants in the general population rather than patients with a prior CVE. At the same time, among limited existing investigations related to patients with established $\mathrm{CAD}$, inconsistent results were also observed. A recent cohort study support that in patients with stable CAD and chronic total occlusion, increased $\mathrm{Lp}(\mathrm{a})$ confers greater risk for poor coronary collateralization when TC, LDL-C or non-HDL-C are elevated especially in patients with T2DM [32]. In the previous study involving stable CAD patients with different glucose metabolism status, high Lp(a) were associated with significantly higher risk of subsequent CVEs in pre-DM and DM [15]. However, the enrolled population were restricted to patients with stable CAD but not those with prior CVEs. On the contrary, Schwartz GG, et al. enrolled 969 patients who experienced a recent ACS and treated with statins, $\mathrm{Lp}(\mathrm{a})$ concentration was not associated with adverse CVEs [16]. Additionally, the study conducted by Gencer et al. also suggested that high Lp(a) levels are not predictive for cardiovascular outcomes in patients otherwise medically well controlled, but might be useful to identify patients who would not be on LDL-C targets 1 year after ACS [33]. The above two studies were localized in patients with the acute setting of ACS, and could not reflect the situation of DM with previous ASCVD attack. Therefore, studies concerning the prognosis of $\mathrm{Lp}(\mathrm{a})$ in patients with a prior CVE are of worth in the real-world, particularly in patients with T2DM.

Consequently, in our study, we observed that Lp(a) levels were significantly higher in patients suffered recurrent CVEs. Of note, our current data also demonstrated that the event-free survival rate was dramatically lower in medium and high Lp(a) groups. Significantly, compared with patients with low Lp(a) levels, those with high Lp(a) had a 2.049-fold higher hazard ratio of recurrent CVEs after adjusting for other variables including LDLC, HBA1c, and so forth. Furthermore, when divided the population into two groups by HBA1c status, the predictive value of $L p(a)$ in risk of recurrent CVEs remains significant independent of the glucose control level. Finally, the C-statistic was significantly improved by 0.029 when added Lp(a) to the Cox model. Although the results were inconsistent with the study conducted by Schwartz GG [16], the different of enrolled population may partly explain the disparity. As far as we know, it is the first large study involved T2DM patients with a first CVE, which included the composite of MI, stroke, peripheral arterial disease, PCI, and CABG, instead of ACS or other specific status. Hence, the present study supported the opinion that $\mathrm{Lp}(\mathrm{a})$ was an independent predictor for recurrent CVEs in T2DM patients with prior CVEs in the stain era.

Till now, the mechanisms of $\mathrm{Lp}(\mathrm{a})$ potentiates CVD risk can be broadly classified in 3 categories: proatherogenic, proinflammatory, and potentially antifibrinolytic [29]. However, the exact mechanism of $\mathrm{Lp}(\mathrm{a})$ increasing CVD risk in DM status was not well clarified. The recent study assessed the relevance of biomarkers combined to pathway groups for the development of T2DM and coronary 
Table 3 Relation of Lp(a) levels with composite and separate recurrent CVEs in patients with T2DM

\begin{tabular}{|c|c|c|c|c|c|}
\hline \multirow[t]{2}{*}{ Endpoints } & \multirow{2}{*}{$\begin{array}{l}\text { Recurrent CVEs/ } \\
\text { Total }\end{array}$} & \multicolumn{2}{|l|}{ Crude model } & \multicolumn{2}{|l|}{ Adjusted model } \\
\hline & & HR $(95 \% \mathrm{Cl})$ & p value & HR $(95 \% \mathrm{Cl})$ & $\mathrm{p}$ value \\
\hline Composite recurrent CVEs & $153 / 2284$ & & & & \\
\hline Lp(a) per-SD increase & & $1.007(1.002-1.013)$ & 0.007 & $1.008(1.002-1.014)$ & 0.006 \\
\hline $\operatorname{Lp}(\mathrm{a})<10$ & $37 / 846$ & Reference & & Reference & \\
\hline $10 \leq L p(a)<30$ & $59 / 769$ & $1.736(1.151-2.619)$ & 0.009 & $1.720(1.099-2.692)$ & 0.018 \\
\hline$L p(a) \geq 30$ & $57 / 669$ & $1.960(1.296-2.965)$ & 0.001 & $2.049(1.308-3.212)$ & 0.002 \\
\hline Non-fatal Ml & $30 / 2284$ & & & & \\
\hline Lp(a) per-SD increase & & $1.012(1.001-1.023)$ & 0.039 & $1.012(1.000-1.024)$ & 0.050 \\
\hline $\operatorname{Lp}(\mathrm{a})<10$ & $7 / 846$ & Reference & & Reference & \\
\hline $10 \leq L p(a)<30$ & $8 / 769$ & $1.259(0.457-3.472)$ & 0.656 & $1.539(0.529-4.474)$ & 0.428 \\
\hline $\operatorname{Lp}(a) \geq 30$ & $15 / 669$ & $2.737(1.116-6.714)$ & 0.028 & $3.016(1.144-7.949)$ & 0.026 \\
\hline Stroke & $55 / 2284$ & & & & \\
\hline Lp(a) per-SD increase & & $1.002(0.992-1.011)$ & 0.761 & $1.001(0.990-1.012)$ & 0.815 \\
\hline $\operatorname{Lp}(a)<10$ & $17 / 846$ & Reference & & Reference & \\
\hline $10 \leq L p(a)<30$ & $22 / 769$ & $1.408(0.748-2.651)$ & 0.289 & $1.355(0.674-2.724)$ & 0.394 \\
\hline$L p(a) \geq 30$ & $16 / 669$ & $1.199(0.606-2.372)$ & 0.603 & $1.118(0.518-2.413)$ & 0.777 \\
\hline CVD deaths & $68 / 2284$ & & & & \\
\hline Lp(a) per-SD increase & & $1.009(1.002-1.017)$ & 0.019 & $1.011(1.003-1.020)$ & 0.011 \\
\hline $\operatorname{Lp}(\mathrm{a})<10$ & $13 / 846$ & Reference & & Reference & \\
\hline $10 \leq L p(a)<30$ & $29 / 769$ & $2.419(1.257-4.652)$ & 0.008 & $2.242(1.108-4.535)$ & 0.025 \\
\hline$L p(a) \geq 30$ & $26 / 669$ & $2.539(1.305-4.942)$ & 0.006 & $2.708(1.340-5.475)$ & 0.006 \\
\hline
\end{tabular}

The adjusted model including age, sex, body mass index, current smoking, hypertension, dyslipidemia, family history of coronary artery disease, diseased vessels, lowdensity lipoprotein cholesterol, fasting blood glucose, statin and anti-diabetes drugs use

CVEs cardiovascular events, MI myocardial infarction, CVD cardiovascular disease

Table 4 Association of Lp(a) levels with recurrent CVEs in T2DM patients according to HBA1c status

\begin{tabular}{|c|c|c|c|c|c|}
\hline \multirow[t]{2}{*}{$\mathrm{Lp}(\mathrm{a})(\mathrm{mg} / \mathrm{dL})$} & \multirow{2}{*}{$\begin{array}{l}\text { Recurrent CVEs/Total } \\
(153 / 2284)\end{array}$} & \multicolumn{2}{|l|}{ Crude model } & \multicolumn{2}{|l|}{ Adjusted model } \\
\hline & & $\mathrm{HR}(95 \% \mathrm{Cl})$ & $p$ value & $\mathrm{HR}(95 \% \mathrm{CI})$ & $p$ value \\
\hline Total patients & $153 / 2284$ & & & & \\
\hline Lp(a) per-SD increase & & $1.007(1.002-1.013)$ & 0.007 & $1.008(1.002-1.014)$ & 0.006 \\
\hline $\operatorname{Lp}(a)<10$ & $37 / 846$ & Reference & & Reference & \\
\hline $10 \leq \mathrm{Lp}(\mathrm{a})<30$ & $59 / 769$ & $1.736(1.151-2.619)$ & 0.009 & $1.720(1.099-2.692)$ & 0.018 \\
\hline$L p(a) \geq 30$ & $57 / 669$ & $1.960(1.296-2.965)$ & 0.001 & $2.049(1.308-3.212)$ & 0.002 \\
\hline $\mathrm{HBA} 1 \mathrm{c}<7.0 \%$ & $74 / 1146$ & & & & \\
\hline Lp(a) per-SD increase & & $1.008(1.001-1.016)$ & 0.024 & 1.009 (1.001-1.018) & 0.023 \\
\hline $\operatorname{Lp}(a)<10$ & $17 / 427$ & Reference & & Reference & \\
\hline $10 \leq L p(a)<30$ & $28 / 373$ & $1.968(1.077-3.595)$ & 0.028 & $1.815(0.949-3.473)$ & 0.072 \\
\hline$L p(a) \geq 30$ & $29 / 346$ & $2.156(1.185-3.924)$ & 0.012 & $2.009(1.051-3.840)$ & 0.035 \\
\hline $\mathrm{HBA} 1 \mathrm{c} \geq 7.0 \%$ & 79/1138 & & & & \\
\hline Lp(a) per-SD increase & & 1.006 (0.998-1.014) & 0.122 & 1.009 (1.000-1.018) & 0.050 \\
\hline $\operatorname{Lp}(a)<10$ & $20 / 418$ & Reference & & Reference & \\
\hline $10 \leq L p(a)<30$ & $31 / 402$ & $1.520(0.866-2.667)$ & 0.144 & $1.571(0.842-2.932)$ & 0.155 \\
\hline$L p(a) \geq 30$ & $28 / 318$ & $1.816(1.023-3.223)$ & 0.042 & $2.162(1.148-4.073)$ & 0.017 \\
\hline
\end{tabular}

The adjusted model including age, sex, body mass index, currentis smoking, hypertension, dyslipidemia, family history of coronary artery disease, diseased vessels, low-density lipoprotein cholesterol, fasting blood glucose, statin and anti-diabetes drugs use

CVEs cardiovascular events, MI myocardial infarction, CVD cardiovascular disease 


\begin{tabular}{|c|c|c|c|}
\hline Models & $\begin{array}{l}\text { C-statistic (95\% } \\
\text { Cl) }\end{array}$ & $\begin{array}{l}\Delta \mathrm{C} \text {-statistic }(95 \% \\
\mathrm{Cl})\end{array}$ & $\mathrm{p}$ value \\
\hline \multicolumn{4}{|c|}{ Total patients $(n=2284)$} \\
\hline Original model & $0.660(0.595-0.726)$ & Reference & \\
\hline $\begin{array}{l}\text { Original model } \\
\quad+L p(a) \\
\text { categories }\end{array}$ & $0.689(0.625-0.753)$ & $0.029(0.006-0.062)$ & 0.047 \\
\hline
\end{tabular}

Original model was using the SMART risk score model

heart disease (CHD) during the median of 14 years follow-up. The authors finally demonstrated that Lp(a) was inversely associated with T2DM and positively with CHD development [34]. However, the potentially causal mechanisms for both diseases, especially in relation to the observed opposite effect directions, are currently still obscure. More investigations were needed in the future.

Nevertheless, our study had several limitations. First of all, this is a study among Chinese population with T2DM and prior CVEs, and whether the data applied to other populations need to be testified. Secondly, the Lp(a) concentrations were only measured at baseline, and the alterations of the biomarkers may also be clinically significant during the follow-up period. Moreover, the method of $\mathrm{Lp}(\mathrm{a})$ measurement used in the study might be influenced by the apo(a) size due to the numbers of the KIV type 2 domain. Variations of apo(a) size between assay calibrators and patients' samples might overestimate or underestimate the real concentration of $\mathrm{Lp}(\mathrm{a})$. Finally, as this was an observational study, further investigations are needed to clarify the underlying mechanism of the associations.

\section{Conclusions}

Our data for the first time indicated that $L p(a)$ was an independent predictor for recurrent CVEs in T2DM patients with prior CVEs, suggesting that $\mathrm{Lp}(\mathrm{a})$ measurement may help further risk stratification for T2DM patients after they suffered a first CVE.

\section{Supplementary information}

Supplementary information accompanies this paper at https://doi. org/10.1186/s12933-020-01083-8.

Additional file 1. Additional tables. Table S1. Relation of $L p(a)$ levels with recurrent CVEs in T2DM patients without $C A B G$, peripheral arterial disease, and stroke. Table S2. Association of exposure and other variables with recurrent CVEs in patients with T2DM.

\section{Abbreviations}

ACS: Acute coronary syndrome; ASCVD: Atherosclerotic cardiovascular disease; CABG: Coronary artery bypass grafting; CAD: Coronary artery disease; CVD: Cardiovascular disease; CVEs: Cardiovascular events; HDL-C: High-density lipoprotein cholesterol; LDL-C: Low-density lipoprotein cholesterol; Lp(a): Lipoprotein(a); MI: Myocardial infarction; PCl: Percutaneous coronary intervention; TC: Total cholesterol; TG: Triglyceride.

\section{Acknowledgements \\ The authors wish to thank the participants and staff of this prospective population study.}

\section{Authors' contributions}

Y-Z completed the project, analyzed data, and wrote the manuscript. J-LJ, YX-C, H-WZ and R-XX contributed to data collection. QH and Y-FL contributed to the collections of data. Y-LG, N-QW, YG, and C-GZ contributed to recruitment of patients, and clinical diagnosis of disease. J-JL designed the study, interpreted data, and contributed to critically revising the manuscript. J-JL is the guarantor of this work and, and takes responsibility for the integrity of the data and the accuracy of the data analysis. All authors read and approved the final manuscript.

\section{Funding}

This work was partially supported by the Capital Health Development Fund (201614035), CAMS Major Collaborative Innovation Project (2016-I2M-1-011) awarded by Dr. Jian-Jun Li, MD, PhD.

The study sponsors did not participate in the study design; the collection, analysis, or interpretation of data; the writing of the manuscript; or the decision to submit the manuscript for publication.

\section{Availability of data and materials}

The datasets used and/or analyzed during the current study are available from the corresponding author on reasonable request.

\section{Ethics approval and consent to participate}

The study complied with the principles of the Declaration of Helsinki and was approved by the ethical review board of Fuwai Hospital (Beijing, China). Written informed consent was obtained from all participants.

\section{Consent for publication}

Not applicable.

\section{Competing interests}

The authors declare that they have no competing interests.

\section{Author details \\ ${ }^{1}$ State Key Laboratory of Cardiovascular Disease, FuWai Hospital, National Center for Cardiovascular Diseases, Chinese Academy of Medical Sciences, Peking Union Medical College, BeiLiShi Road 167, Beijing 100037, China. \\ 2 Department of Cardiology, Xuanwu Hospital, Capital Medical University, Beijing, China. ${ }^{3}$ Department of Cardiology, Beijing Anzhen Hospital, Capital Medical University, Beijing, China.}

Received: 23 April 2020 Accepted: 2 July 2020

Published online: 09 July 2020

\section{References}

1. American Diabetes Association. Standards of medical care in diabetes-2017. Diabetes Care. 2017;40(suppl 1):S1-135.

2. American Diabetes Association. (9) Cardiovascular Disease and Risk Management: standards of Medical Care in Diabetes-2018. Diabetes Care. 2018;41(Suppl 1):S86-104.

3. Handelsman Y, Lepor NE. PCSK9 inhibitors in lipid management of patients with diabetes mellitus and high cardiovascular risk: a review. J Am Heart Assoc. 2018;7(13):e008953.

4. Koskinas KC, Siontis GC, Piccolo R, et al. Impact of diabetic status on outcomes after revascularization with drug-eluting stents in relation to coronary artery disease complexity: patient-level pooled analysis of 6081 patients. Circ Cardiovasc Interv. 2016;9:e003255. 
5. Gerstein HC, Miller ME, Byington RP, et al. Action to Control Cardiovascular Risk in Diabetes Study Group Effects of intensive glucose lowering in type 2 diabetes. N Engl J Med. 2008;358:2545-59.

6. Nordestgaard BG, Chapman MJ, Ray K, et al. Lipoprotein(a) as a cardiovascular risk factor: current status. Eur Heart J. 2010;31:2844-53.

7. Erqou S, Kaptoge S, Perry PL, et al. Lipoprotein(a) concentration and the risk of coronary heart disease, stroke, and nonvascular mortality. JAMA. 2009;302:412-23.

8. Kamstrup PR, Tybjaerg-Hansen A, Steffensen R, et al. Genetically elevated lipoprotein(a) and increased risk of myocardial infarction. JAMA. 2009;301:2331-9.

9. Waldeyer C, Makarova N, Zeller T, et al. Lipoprotein(a) and the risk of cardiovascular disease in the European population: results from the BiomarCaRE consortium. Eur Heart J. 2017;38:2490-8.

10. Saeed A, Sun W, Agarwala A, et al. Lipoprotein(a) levels and risk of cardiovascular disease events in individuals with diabetes mellitus or prediabetes: the Atherosclerosis Risk in Communities study. Atherosclerosis. 2019:282:52-6.

11. O'Donoghue ML, Morrow DA, Tsimikas S, et al. Lipoprotein(a) for risk assessment in patients with established coronary artery disease. J Am Coll Cardiol. 2014;63:520-7.

12. Konishi H, Miyauchi K, Kasai T, et al. Impact of lipoprotein(a) as residual risk on long-term outcomes in patients after percutaneous coronary intervention. Am J Cardiol. 2015;115:157-60.

13. Konishi H, Miyauchi K, Tsuboi S, et al. Plasma lipoprotein(a) predicts major cardiovascular events in patients with chronic kidney disease who undergo percutaneous coronary intervention. Int J Cardiol. 2016;205:50-3.

14. Zhang HW, Zhao X, Guo YL, et al. Elevated lipoprotein (a) levels are associated with the presence and severity of coronary artery disease in patients with type 2 diabetes mellitus. Nutr Metab Cardiovasc Dis. 2018;28:980-6.

15. Jin JL, Cao YX, Zhang HW, et al. Lipoprotein(a) and cardiovascular outcomes in patients with coronary artery disease and prediabetes or diabetes. Diabetes Care. 2019;42(7):1312-8.

16. Schwartz GG, Ballantyne CM, Barter PJ, et al. Association of Lipoprotein(a) with risk of recurrent ischemic events following acute coronary syndrome: analysis of the dal-outcomes randomized clinical trial. JAMA Cardiol. 2018;3:164-8.

17. Zewinger S, Kleber ME, Tragante $V$, et al. Relations Between Lipoprotein(a) concentrations, Ipa genetic variants, and the risk of mortality in patients with established coronary heart disease: a molecular and genetic association study. Lancet Diabetes Endocrinol. 2017;5:534-43.

18. Dorresteijn JA, Visseren FL, Wassink AM, et al. Development and validation of a prediction rule for recurrent vascular events based on a cohort study of patients with arterial disease: the SMART risk score. Heart. 2013;99:866-72

19. Tsimikas S. A test in context: lipoprotein(a): diagnosis, prognosis, controversies, and emerging therapies. J Am Coll Cardiol. 2017;69:692-711.

20. Li S, Wu NQ, Zhu CG, et al. Significance of lipoprotein(a) levels in familial hypercholesterolemia and coronary artery disease. Atherosclerosis. 2017;260:67-74
21. Stone GW, Maehara A, Lansky AJ, et al. A prospective natural-history study of coronary atherosclerosis. N Engl J Med. 2011;364(3):226-35.

22. Haffner SM, Lehto $S$, Ronnemaa T, et al. Mortality from coronary heart disease in subjects with type 2 diabetes and in nondiabetic subjects with and without prior myocardial infarction. N Engl J Med. 1998;339(4):229-34

23. Whiting $D R$, Guariguata $L$, Weil $C$, et al. global estimates of the prevalence of diabetes for 2011 and 2030. Diabetes Res Clin Pract. 2011;94:311-21.

24. Rawshani A, Franzén S, Eliasson B, et al. Mortality and cardiovascular disease in type 1 and type 2 diabetes. N Engl J Med. 2017;376:1407-18.

25. Kavousi M, Leening MJ, Nanchen D, et al. Comparison of application of the ACC/AHA guidelines, Adult Treatment Panel III guidelines, and European Society of Cardiology guidelines for cardiovascular disease prevention in a European cohort. JAMA. 2014;311:1416-23.

26. Cziraky MJ, Reddy VS, Luthra R, et al. Clinical Outcomes and Medication Adherence in Acute Coronary Syndrome Patients With and Without Type 2 Diabetes Mellitus: a Longitudinal Analysis 2006-2011. J Manag Care Spec Pharm. 2015:21:470-7.

27. Kumar A, Singh V. Atherogenic dyslipidemia and diabetes mellitus: what's new in the management arena? Vasc Health Risk Manag. 2010;6:665-9.

28. The Task Force for the management of dyslipidaemias of the European Society of Cardiology (ESC) and European Atherosclerosis Society (EAS). ESC/EAS Guidelines for the management of dyslipidaemias: lipid modification to reduce cardiovascular risk. Eur Heart J. 2019;2019:1-78.

29. Gencer B, Kronenberg F, Stroes ES, et al. Lipoprotein(a): the revenant. Eur Heart J. 2017;38:1553-60.

30. Langsted A, Kamstrup PR, Nordestgaard BG. High lipoprotein(a) and high risk of mortality. Eur Heart J. 2019;40:2760-70.

31. Clarke R, Peden JF, Hopewell JC, et al. Genetic Variants Associated With Lp(a) Lipoprotein Level and Coronary Disease. N Engl J Med. 2009;361:2518-28.

32. Shen Y, Chen S, Dai Y, et al. Lipoprotein (a) interactions with cholesterolcontaining lipids on angiographic coronary collateralization in type 2 diabetic patients with chronic total occlusion. Cardiovasc Diabetol. 2019;18:82.

33. Gencer B, Rigamonti F, Nanchen D, et al. Prognostic value of elevated lipoprotein(a) in patients with acute coronary syndromes. Eur J Clin Invest. 2019:49:e13117.

34. Huth C, Bauer A, Zierer A, et al. Biomarker-defined Pathways for Incident Type 2 Diabetes and Coronary Heart Disease-A Comparison in the MONICA/KORA Study. Cardiovasc Diabetol. 2020;19(1):32.

\section{Publisher's Note}

Springer Nature remains neutral with regard to jurisdictional claims in published maps and institutional affiliations.

\footnotetext{
Ready to submit your research? Choose BMC and benefit from:

- fast, convenient online submission

- thorough peer review by experienced researchers in your field

- rapid publication on acceptance

- support for research data, including large and complex data types

- gold Open Access which fosters wider collaboration and increased citations

- maximum visibility for your research: over 100M website views per year
}

At BMC, research is always in progress.

Learn more biomedcentral.com/submissions 